Article

\title{
Thermo-Catalytic Treatment of Vapors in the Recycling Process of Carbon Fiber-Poly (Benzoxazine) Composite Waste by Pyrolysis
}

\author{
Naia Gastelu ${ }^{1}$, Alexander Lopez-Urionabarrenechea ${ }^{1, * \mathbb{C}}$, Jon Solar ${ }^{1}{ }^{\mathbb{C}}$, Esther Acha ${ }^{1}$, \\ Blanca María Caballero ${ }^{1}$, Félix A. López ${ }^{2}$ (D) and Isabel de Marco ${ }^{1}$ (D) \\ 1 Chemical and Environmental Engineering Department, Faculty of Engineering of Bilbao, \\ University of the Basque Country (UPV/EHU), Plaza Ingeniero Torres Quevedo 1, 48013 Bilbao, Spain; \\ naia.gastelu@ehu.eus (N.G.); jon.solar@ehu.eus (J.S.); esther.acha@ehu.eus (E.A.); \\ blancamaria.caballero@ehu.eus (B.M.C.); isabel.demarco@ehu.eus (I.d.M.) \\ 2 National Center for Metallurgical Research (CENIM-CSIC), Av. Gregorio del Amo 8, 28040 Madrid, Spain; \\ f.lopez@csic.es \\ * Correspondence: alex.lopez@ehu.eus; Tel.: +34-946-018-245
}

Received: 28 September 2018; Accepted: 30 October 2018; Published: 6 November 2018

\begin{abstract}
Recycling carbon fiber from residual carbon fiber reinforced plastics (CFRP) is one of the key aspects of the future in the field of waste management. This work presents the possibility of recovering chemical compounds through the thermo-catalytic treatment of the gases and vapors produced from the decomposition of the polymeric resin that takes place in the recycling of CFRP by pyrolysis. A lab-scale installation consisting of two reactors placed in series has been used for the experiments. In the first reactor, pyrolysis of poly(benzoxazine)-based composite waste has been carried out at $500{ }^{\circ} \mathrm{C}$. In the second reactor, the thermo-catalytic treatment of gases and vapors has been performed at $900{ }^{\circ} \mathrm{C}$ in the presence of a commercial and a lab-prepared reforming catalyst. The thermal treatment of gases and vapors leads to a significant reduction in the collected liquids and $\mathrm{H}_{2}$-rich gas fraction. When reforming catalysts are used, the organic fraction of the liquids is virtually eliminated and gas fractions containing more than $50 \% \mathrm{H}_{2}$ in volume are generated. The results obtained show that it is possible to valorize the material content of the polymer resin, which represents an important advance in the recycling of CFRP by pyrolysis.
\end{abstract}

Keywords: CFRP; carbon fiber; recycling; pyrolysis; catalytic reforming; hydrogen production; poly(benzoxazine); composite

\section{Introduction}

The incorporation of carbon fiber reinforced polymers / plastics (CFRP) into the manufacturing of components has been a revolution. CFRP is increasingly being employed in place of conventional materials such as steel, aluminum or non-ferrous alloys, since the physical-chemical properties of CFRP are similar, or even superior, to those of the materials traditionally used in manufacturing, while their weight is much lower [1]. A CFRP is a polymer, usually a thermoset resin, internally reinforced with carbon fiber $(\mathrm{CF})$. Its high performance is due to the presence of $\mathrm{CF}$, which is a material of exceptional characteristics, with very good mechanical, electrical and thermal properties, and at the same time, very low density [2].

Estimates of CF demand calculate that around $60 \mathrm{Mt}$ of this material was consumed in 2015, and according to all predictions, the increase in demand during the next decade is a fact, with figures ranging from $140 \mathrm{Mt}$ by 2020 to $175 \mathrm{Mt}$ by 2025 [3,4]. Such spectacular CF consumption estimations suggests a high potential for CFRP waste generation in the future, as CF is used almost exclusively to 
manufacture composite materials [5]. Therefore, there is a clear need for a circular economy model to recover carbon fibers from waste and reintroduce them as secondary raw materials instead of disposing of them in landfills or burning them in incineration facilities, which are the two most commonly used options nowadays [6].

The main CFRP waste recycling methods that have been studied to date can be divided into mechanical treatments, chemical treatments and thermal treatments. Mechanical treatment consists of grinding the waste to reuse it in low-value reinforcement applications, while through chemical and thermal methods, the polymeric resin is eliminated so the CF can be recovered and consequently reused in new composites. In the chemical treatment, the CF recycling is done by the dissolution of the resin, and in the thermal case, by the decomposition and/or oxidation of the polymer. These processes are explained in detail in review publications that can be found in the literature [7-9]. Among them, pyrolysis (heating in absence of oxygen) is the most developed technique to date, as is evidenced by some commercial plants that employ this technique to recycle CF: ELG Carbon Fibre (United Kingdom), Carbon Conversions (USA), CFK Valley Recycling (Germany), Karborek (Italy) and Carbon Fiber Recycle Industry (Japan) [10]. However, the recycling of CFRP waste by pyrolysis has not reached the level of implementation that the production rate of this waste requires today and will require in the future. There are studies indicating that the recycling process still needs to be more profitable through the material recovery of the polymer resin (recovery of chemical compounds), since in existing industrial processes, the organic gases and vapors generated due to the resin decomposition are just burned [6].

As is to be expected, giving utility to the gases and condensed vapors from the decomposition of the polymer resins is not an easy task. The research carried out up to now has mainly focused on CFRP with epoxy and poly(benzoxazine) matrices, because these CFRP are intensively used in aerospace applications [5,11-15]. Specifically, the research carried out with poly(benzoxazine)-based CFRP indicate that the liquids formed are very complex mixtures of hydrocarbons, nitrogenous, oxygenated and even sulfuric organic compounds, often mixed with water $[11,14,15]$. The gaseous fraction, which is generated in very small quantities, is composed of carbon monoxide and dioxide, hydrogen and light hydrocarbons [14,15]. The gas could be used as an alternative fuel, but the benefit obtained from its use would not compensate the problem of the liquid products: the industrial use of these liquids is unlikely, with the result that, given its composition, it would be classified as a hazardous waste.

Nevertheless, no research group to date has studied whether it is possible to obtain valuable chemical compounds through the treatment of the condensable vapors and permanent gases generated in the pyrolysis of poly(benzoxazine)-based CFRP waste. In this context, this article presents for the first time the results obtained in the thermo-catalytic treatment of these byproducts before condensing them, that is, in gas phase. The aim of the research is to generate value-added chemical compounds and thus valorize the resin as a material; this may be a key step forward in the large-scale development of CFRP waste recycling.

\section{Results and Discussion}

\subsection{Characterization of the CFRP Waste}

The residual CFRP used in this work is an expired pre-impregnated form from the aeronautical industry composed of a poly(benzoxazine) resin and reinforced with Toray T300/3k carbon fibers of $7 \mu \mathrm{m}$ diameter. The proximate and elemental analyses, together with the fiber content of the waste CFRP sample, can be seen in Table 1. Table 1 also includes the results of the same analyses applied to the carbon fiber of this CFRP, with the aim of comparison. This CF was obtained by applying the D3171 method of the American Society for Testing and Materials (ASTM), which consists of the dissolution of the resin in a $\mathrm{H}_{2} \mathrm{SO}_{4} / \mathrm{H}_{2} \mathrm{O}_{2}$ mixture. As can be seen, the fiber content of the sample is 61 weight percent (wt.\%), which is in line with some published fiber content values for pre-impregnated poly(benzoxazine)-CF composites [14,15]. As far as the proximate analysis of the 
CFRP waste is concerned, the moisture and ash contents are very low, so the sample is mainly composed of volatiles and fixed carbon. If the results of the proximate analysis of the CF are examined, it can be seen that the carbon fibers are almost entirely fixed carbon, which can give an idea of their thermal stability, and in addition, they have neither moisture nor ashes. Therefore, it can be concluded that the volatiles in the CFRP sample come mainly from the resin, while the fixed carbon corresponds largely to the carbon fibers. Furthermore, it can be said that moisture and ash derive from the resin; the moisture is probably water adsorbed from the environment, while the ashes could be inorganic fillers of the resin composition.

Table 1. Fiber content, proximate and elemental analyses of the waste carbon fiber reinforced plastics (CFRP) and carbon fiber (CF) recovered after applying the ASTM D3171 method to the CFRP waste (weight percentage (wt.\%), as received basis).

\begin{tabular}{|c|c|c|}
\hline \multirow{2}{*}{\multicolumn{2}{|c|}{ CFRP Waste }} & \multirow{2}{*}{$\mathrm{CF}$} \\
\hline & & \\
\hline Fiber content & 61.0 & 100.0 \\
\hline \multicolumn{3}{|c|}{ Proximate analysis } \\
\hline Moisture & 0.5 & 0.0 \\
\hline Volatiles & 28.4 & 6.2 \\
\hline Fixed carbon ${ }^{1}$ & 71.0 & 93.8 \\
\hline Ash & 0.1 & 0.0 \\
\hline \multicolumn{3}{|c|}{ Elemental analysis } \\
\hline $\mathrm{C}$ & 86.2 & 95.7 \\
\hline $\mathrm{H}$ & 2.2 & 0.1 \\
\hline $\mathrm{N}$ & 4.8 & 2.8 \\
\hline$S$ & 1.3 & 0.1 \\
\hline $\mathrm{Cl}$ & u.d.l. ${ }^{2}$ & u.d.1. ${ }^{2}$ \\
\hline Others ${ }^{3}$ & 4.9 & 1.3 \\
\hline
\end{tabular}

The carbon fiber elemental analysis serves to discuss the origin of the different elements found in the CFRP sample. Table 1 shows that the carbon fiber is composed mainly of carbon and small quantities of nitrogen and "others". Nitrogen is probably a remnant of the fiber production process, since in most cases, poly(acrylonitrile) is used as a precursor of CF [2]. On the other hand, taking into account that the surface treatments of carbon fibers are usually oxidative, "others" are expected to be mainly oxygen [16]. The elemental analysis of the CFRP sample clearly shows that resin provides the hydrogen, sulfur, and some more nitrogen and "others" content. Hydrogen and nitrogen derive from the resin itself, since benzoxazine monomers are usually synthesized from phenols, amines and formaldehyde $[17,18]$. For the same reason, it can be stated that the "others" group is mainly oxygen. On the contrary, the presence of sulfur cannot be directly related to the composition of the resin monomers, but probably to sulphur-containing crosslinking agents [19]. In any case, the elemental analysis of this poly(benzoxazine) CFRP sample is very similar to other poly(benzoxazine) CFRP compositions in literature [14,15].

Figure 1 shows the dynamic thermogravimetric analysis of the CFRP waste. As it can be seen, the sample shows a main decomposition process in the temperature range between $330{ }^{\circ} \mathrm{C}$ and $465^{\circ} \mathrm{C}$, with the maximum decomposition rate at $391{ }^{\circ} \mathrm{C}$. In this temperature range, the sample loses approximately $23 \%$ of its initial weight and then shows a light constant rate weight loss up to $1000{ }^{\circ} \mathrm{C}$. By this temperature, the sample weight loss is $29.4 \%$ of the initial mass. These weight loss values are in agreement with the results reported by other authors concerning the decomposition of phenolic resins containing carbon fiber reinforcement [12]. Such authors attributed the steady weight loss of the sample to volatilization of carbonaceous products formed due to carbonization reactions that occur during polymer decomposition. Carbon fibers are highly stable in a nitrogen atmosphere up to $1000{ }^{\circ} \mathrm{C}$ 
and only undergo a small weight loss $(\approx 1 \mathrm{wt} . \%)$ between $300{ }^{\circ} \mathrm{C}$ and $400{ }^{\circ} \mathrm{C}$ due to the decomposition of the sizing agent, so they do not lose weight appreciably in such heating process [20,21].

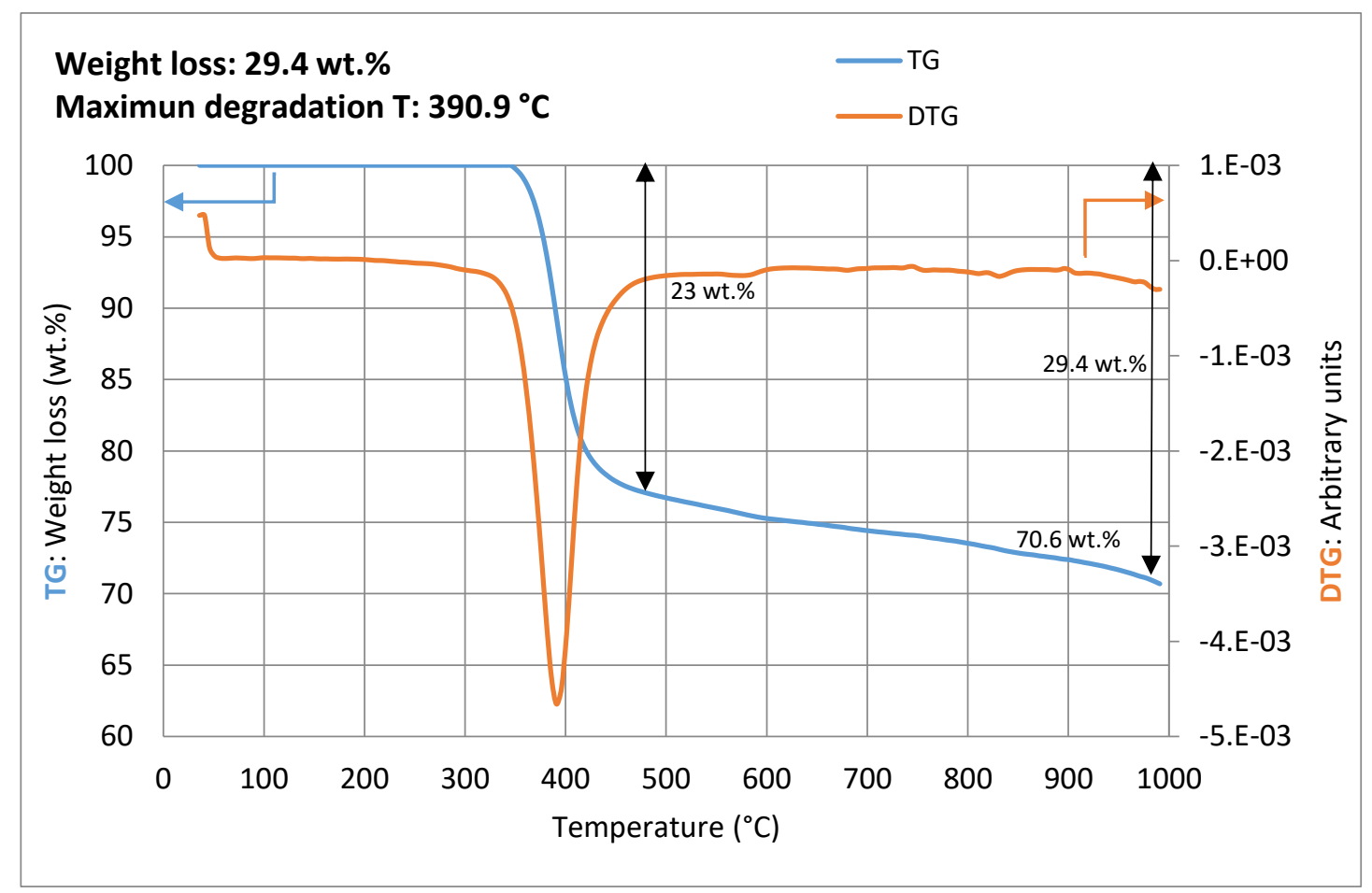

Figure 1. Thermogravimetric analysis of the waste CFRP in a $\mathrm{N}_{2}$ atmosphere.

The carbonization reactions explain the fact that the weight loss at $1000{ }^{\circ} \mathrm{C}(29.4 \mathrm{wt} . \%)$ is lower than the amount of resin present in the CFRP (from Table 1, amount of resin $=100-61.0$ $=39.0 \mathrm{wt} . \%$ ). It is a well-known fact that the majority of the thermosetting resins (especially the benzoxazine-based ones) yield a carbonaceous product called char when decomposing in a non-oxidizing atmosphere $[17,20,22,23]$. The char remains in the surface of the carbon fibers and cannot be eliminated by temperature in absense of oxygen. That is, the poly(benzoxazine) resin is not completely removed only by the presence of heat and this fact explains why the remaining mass after the analysis (70.6 wt.\%) does not correspond to the fiber content of the sample (61.0 wt.\%).

\subsection{Pyrolysis Experiments and Gas/Liquid Composition}

A series of pyrolysis experiments at $500{ }^{\circ} \mathrm{C}$ were carried out at two different heating rates and by applying different treatments to the pyrolysis vapors and gases. In such treatments, two catalysts were used: a commercial reforming catalyst composed of Ni on alumina and a ZSM- 5 zeolite doped with Ni. Table 2 shows the pyrolysis yields obtained in the experiments carried out, together with the composition of the gases and liquids obtained in such experiments.

The E1 experiment represents a typical pyrolysis run, with an intermediate heating rate and no treatment of vapors and gases. The results of this experiment show that the main product of CFRP waste pyrolysis is the solid fraction, where the carbon fibers are, followed by the condensed products and finally a small amount of gas. These results are in agreement with those obtained by other authors in the pyrolysis of benzoxazine and epoxy-based CFRP $[5,12,14,15,24]$. The solids yield is greater than the carbon fiber content of the sample, which is to be expected from the thermogravimetric analysis shown in Figure 1. Indeed, the solids yield is very similar to the remnant weight in that analysis at $500{ }^{\circ} \mathrm{C}$. Then, around $20 \mathrm{wt} . \%$ of liquid is produced, which is composed of two phases. The aqueous phase is mainly composed of water, while the organic phase is dominated by nitrogenous and oxygenated aromatic compounds, in which aniline and phenol stand out (these are also part of 
the aqueous phase). The presence of water in the liquids of poly(benzoxazine) pyrolysis has also been reported by other authors $[14,15]$. These authors attributed the formation of water to the oxygen containing functional groups, such as $-\mathrm{OH}$ and $-\mathrm{COO}_{-}$, which are present in the matrix chemical composition. The formation of water is also very common in the pyrolysis of oxygenated samples such as biomass $[25,26]$. The dominant presence of aniline and phenol in pyrolysis liquids of benzoxazine type CFRP has been previously reported by other authors and can be explained by the fact that it is very common to employ aniline and phenol derivatives as feedstock to produce this type of polymeric resin [11,14]. Finally, 5\% of gas is also produced, mainly composed of $\mathrm{CH}_{4}, \mathrm{CO}_{2}, \mathrm{H}_{2}$ and $\mathrm{CO}$ and with relatively high heating values (HHV).

Table 2. Pyrolysis experiment conditions, yields and product analyses.

\begin{tabular}{|c|c|c|c|c|c|}
\hline & E1 & E2 & E3 & E4 & E5 \\
\hline Vapor thermal treatment & No & No & $900{ }^{\circ} \mathrm{C}$ & $900^{\circ} \mathrm{C}$ & $900^{\circ} \mathrm{C}$ \\
\hline Catalyst (cat) & No & No & No & Reforming cat & $\mathrm{Ni} / \mathrm{HZSM}-5$ \\
\hline Pyrolysis heating rate $\left({ }^{\circ} \mathrm{C} \min ^{-1}\right)$ & 15 & 3 & 3 & 3 & 3 \\
\hline \multicolumn{6}{|c|}{ Pyrolysis yields (wt.\%) } \\
\hline Solid & 74.8 & 76.9 & 75.2 & 77.1 & 76.3 \\
\hline Total condensates & 20.2 & 16.5 & 10.5 & 10.1 & 10.5 \\
\hline Collected liquid ${ }^{1}$ & 10.4 & 4.4 & 1.4 & 1.5 & 1.8 \\
\hline Aqueous fraction ${ }^{2}$ & 66.5 & 43.8 & 72.4 & 96.0 & 94.2 \\
\hline Organic fraction ${ }^{2}$ & 33.5 & 56.2 & 27.6 & 4.0 & 5.8 \\
\hline Gases $^{3}$ & 5.0 & 6.6 & 14.3 & 12.8 & 13.2 \\
\hline \multicolumn{6}{|c|}{ Composition (vol.\%) and HHV (MJ Nm ${ }^{-3}$ ) of pyrolysis gases } \\
\hline $\mathrm{H}_{2}$ & 18.6 & $<0.1$ & 43.4 & 52.9 & 56.3 \\
\hline $\mathrm{CO}$ & 14.4 & $<0.1$ & 12.9 & 21.0 & 19.1 \\
\hline $\mathrm{CO}_{2}$ & 21.8 & 35.0 & 5.9 & 5.4 & 5.1 \\
\hline $\mathrm{CH}_{4}$ & 34.2 & 64.1 & 24.7 & 15.1 & 15.2 \\
\hline $\mathrm{C} 2$ & 3.7 & $<0.1$ & 6.7 & 2.9 & 2.9 \\
\hline $\mathrm{C} 3$ & $<0.1$ & $<0.1$ & 0.4 & $<0.1$ & $<0.1$ \\
\hline $\mathrm{C} 4$ & $<0.1$ & $<0.1$ & $<0.1$ & $<0.1$ & $<0.1$ \\
\hline C5 & $<0.1$ & $<0.1$ & 0.1 & $<0.1$ & $<0.1$ \\
\hline C6 & 7.2 & 0.8 & 6.0 & 2.8 & 1.5 \\
\hline $\mathrm{HHV}^{4}$ & 30.0 & 24.6 & 29.6 & 20.3 & 18.4 \\
\hline \multicolumn{6}{|c|}{ Composition of pyrolysis liquids (area\%)—aqueous phase } \\
\hline Water & 82.4 & 86.2 & 79.4 & 83.8 & 83.3 \\
\hline Aniline & 6.7 & 13.8 & 13.7 & 16.2 & 16.7 \\
\hline Phenol & 5.9 & n.d. 5 & n.d. 5 & n.d. 5 & n.d. 5 \\
\hline Unidentified & 5.0 & 0.0 & 6.9 & 0.0 & 0.0 \\
\hline \multicolumn{6}{|c|}{ Composition of pyrolysis liquids (area\%)—organic phase } \\
\hline Aniline & 28.4 & 35.3 & 19.3 & 27.5 & 23.1 \\
\hline Other N-aromatics & 11.8 & 2.2 & 29.8 & 33.5 & 38.8 \\
\hline Phenol & 24.7 & 24.3 & n.d. 5 & n.d. ${ }^{5}$ & n.d. 5 \\
\hline Other O-aromatics & 28.0 & 12.9 & n.d. 5 & 1.6 & 3.7 \\
\hline $\mathrm{PAH}^{6}$ & 0.0 & 0.0 & 28.1 & 35.5 & 29.7 \\
\hline Others ${ }^{7}$ & 4.3 & 1.9 & 22.8 & 1.9 & 3.2 \\
\hline Unidentified & 2.8 & 23.4 & 0.0 & 0.0 & 1.5 \\
\hline
\end{tabular}

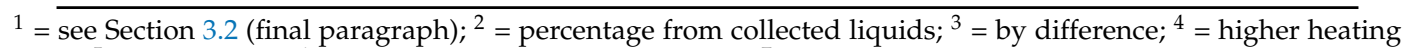
value $;{ }^{5}=$ not detected; ${ }^{6}=$ polycyclic aromatic hydrocarbons; ${ }^{7}=$ others, defined as well identified compounds that do not belong to the chemical families above.

The high generation of liquids, whose industrial utility is very complicated, is the main cause of burning the vapors generated in the existing CFRP recycling processes. The reason is that in the absence of utility, the composition of these liquids makes them classified as hazardous waste, with the 
environmental and economic implications that this entails. Therefore, the following experiments were designed with the aim of reducing the quantity of pyrolysis liquids, and at the same time, enhancing the production of gas that can be used in different industrial aplications. The first step was to decrease the heating rate to $3^{\circ} \mathrm{C} \mathrm{min}^{-1}$ to achieve a slow pyrolysis process (E2 experiment). This decision was taken based on the previous experience of the authors in the investigation of pyrolysis with other type of waste [27].

As shown in Table 2, slow pyrolysis of CFRP (E2) produces a four percentage point reduction in condensates generation, and more importantly, a reduction in more than half of the collected liquids, which are more representative of changes in operating conditions than the condensates that may remain in the pipelines, which are more dependent on plant design. The decrease in condensates yield is evenly distributed, increasing the solid and gas yields. The solid yield increases due to carbonization reactions that can take place at a greater extent when polymeric waste is slowly heated up [27]. The explanation concerning the change between liquid and gas yields could be that slow heating rates make the release of chemical compounds from the decomposition of the resin slower. This has a very important influence on the secondary reactions that can occur between these compounds when they are already in the gas phase. High heating rates generate more compounds in short time intervals, which multiplies the possibilities of the reactions between them. When slow heating rates are used, gas phase interactions occur between fewer compounds [27]. Therefore, the interactions between multiple compounds could favor the formation of condensable products, while the generation of gases is greater when the interactions are smaller. Looking at the composition of liquids, there are no important changes in terms of applicability; that is, the two phases are in significant proportions and have a similar composition. The gas composition is simplified under these slow pyrolysis conditions. In this case, it appears that $\mathrm{CH}_{4}$ and $\mathrm{CO}_{2}$ may be primary decomposition compounds (slow heating rate), which are capable of generating $\mathrm{H}_{2}, \mathrm{CO}$ and other hydrocarbons when in contact with more chemical compounds (rapid heating rate). In any case, the gas fraction retains its potential industrial utility.

The results of the E3 experiment were obtained after adding a thermal treatment of pyrolysis vapors and gases before condensation. Details about this treatment can be found in Section 3.2 of the paper. As Table 2 shows, there is an important change in the yield ratio of liquids and gases after treatment. The total condensates are reduced by half compared to the E1 test, and most of them are condensates in pipelines, as the collected liquids decrease to a negligible by-product. As a consequence, the gases suffer a corresponding increase in yield, becoming the second product of the process. The mentioned behavior is the consequence of cracking reactions of organic molecules that take place at high temperatures during the thermal treatment $[28,29]$. This is a very positive result, as there is a significant reduction in the liquids produced. This fact is even more interesting looking at the composition of the gases, since $\mathrm{H}_{2}$ becomes the main compound in the mixture (more than 40 volume percent (vol.\%)), followed by $\mathrm{CH}_{4}$ (almost $25 \mathrm{vol} . \%$ ), both of which are widely employed in industry. In addition, the amount of $\mathrm{CO}_{2}$ is reduced considerably, causing a relatively high HHV. With regard to the liquids composition, no major changes are observed except for the apparent reactivity of the aniline and the oxygenated compounds of the organic fraction under these cracking conditions, as the proportion of all of them decrease appreciably. Aniline may be converted to other nitrogenous aromatic compounds, while oxygen may pass into the gas phase of the process (including unquantified water vapor). Also noteworthy is the appearance of PAH in the organic fraction, something common in cracking reactions of organic molecules at high temperature [29].

In order to improve the properties of the produced gases and liquids, two catalysts were tested in the E4 and E5 experiments. In E4, a commercial reforming catalyst, $\mathrm{Ni}$ on alumina, was employed, and in E5, a homemade Ni on ZSM-5 zeolite catalyst (prepared in the laboratories from a commercial zeolite) was used. Both have a similar amount of $\mathrm{Ni}(\approx 12 \mathrm{wt} . \%)$ and an approximately equal $\mathrm{Ni}$ crystal size $(\approx 5 \mathrm{~nm})$. The main difference between them is that zeolite is a more acid support, with greater surface development and significantly smaller pores than the reforming commercial catalyst (see Section 3.1). If attention is paid to the yields obtained in these experiments, it can be observed 
that they are very similar to those obtained in the non-catalytic thermal treatment experiment (E3). Condensates and collected liquids appear in the same quantities, while there is a small decrease in the gas yields, which is due to the fact that the yield in solids is slightly higher than that obtained in the E3 experiment. These variations are not very significant, as they fall within the dispersion of the results usually obtained in these experiments. What is worthy of note is the significant decrease in the organic phase of liquids with respect to the thermal treatment experiment (from $27.6 \mathrm{wt} . \%$ to $4.0 / 5.8 \mathrm{wt} . \%$ ). This is another very important result, because the reduction of the amount of the organic phase considerably increases the options of using these liquids, since the aqueous phase consists of a mixture of water and aniline. There is no significant difference between the composition of the organic phases of the E3, E4 and E5 experiments, except that in the organic phases of the thermo-catalytic experiments, there are fewer compounds (a lower percentage of "others" is observed). However, the organic phase yield values of the E4 and E5 experiments correspond to small spots of liquid supernatant in the aqueous phase and on the walls of the condensers, i.e., they are totally negligible quantities in comparison with that of E3 experiment, and of course, in comparison with E1 and E2 experiments.

The composition of the gases also shows the action of the catalysts. In both cases there is a clear reduction in the hydrocarbon content (mainly $\mathrm{CH}_{4}, \mathrm{C} 2$ and C6) in favor of a higher production of $\mathrm{H}_{2}$ and $\mathrm{CO}$, which indicates that both catalysts have promoted reforming reactions. The composition of the gases in the E4 and E5 experiments is practically the same, but a greater amount of $\mathrm{H}_{2}$ can be seen when the zeolite-based catalyst is used. Bearing in mind that the amount of $\mathrm{Ni}$ is very similar in the two catalysts, one of the reasons could be that the zeolite-based catalyst also contributes to the generation of hydrogen through the cracking of organic substances due to its high acidity, producing hydrogen through two different routes (reforming and cracking). In any case, the fact that the amount of hydrogen in the gases is greater than $50 \%$ by volume is not a trivial matter, as it is from this value that the separation of this compound from other gaseous compounds begins to be profitable. In other words, the action of the catalysts allows these gases to be considered as a source of $\mathrm{H}_{2}$, which can be used in any of its multiple industrial applications. These results clearly open the door to the possibility of recovering chemicals from the CFRP polymer resin.

\subsection{Pyrolysis Solids}

Table 3 shows the proximate and elemental analyses of the pyrolysis solids. In this case, only the analysis of the solids obtained in the E1 and E2 experiments has been included, since the operating conditions in the pyrolysis reactor are the same in the E2, E3, E4 and E5 experiments.

Table 3. Proximate and elemental analyses of the pyrolysis solids (wt.\%, as received basis).

\begin{tabular}{ccc}
\cline { 2 - 3 } & \multicolumn{3}{c}{ E1 } & E2 \\
\cline { 2 - 4 } & \multicolumn{3}{c}{ Proximate analysis } \\
\cline { 2 - 3 } Moisture & 0.8 & 0.9 \\
Volatiles & 7.2 & 7.0 \\
Fixed carbon ${ }^{1}$ & 91.9 & 92.0 \\
Ash & 0.1 & 0.1 \\
\hline Elemental analysis \\
\hline C & 91.2 & 91.2 \\
$\mathrm{H}$ & 0.8 & 0.4 \\
$\mathrm{~N}$ & 5.4 & 5.3 \\
$\mathrm{~S}$ & $<0.1$ & $<0.1$ \\
Others & \\
& 2.5 & 3.0 \\
\hline
\end{tabular}


As far as the comparison between the two solids is concerned, neither the proximate analysis nor the elemental analysis reveal important differences caused by the change in the heating rate of the residual CFRP, as they present practically identical results. More interesting is the comparison of these results with those of the proximate and elemental analysis of the carbon fiber in Table 1, as in principle, the solid remaining after the pyrolysis should be recovered carbon fibers. In relation to the proximate analysis, the first difference is that the solids obtained have some moisture in contrast to the carbon fiber, which does not absorb moisture significantly. In addition, carbon fiber has a slightly higher amount of fixed carbon (and therefore a lower amount of volatiles) than the solids obtained after pyrolysis. Similarly, elemental analysis shows that carbon fiber is mainly composed of carbon and nitrogen, while pyrolysis solids have higher amounts of hydrogen, nitrogen and "others", making their percentage of carbon lower (91 wt.\% vs. $96 \mathrm{wt} . \%)$. All of this indicates that, in addition to the carbon fibers, there is probably some other substances in these pyrolysis solids. These substances could be undecomposed resin and/or char, as discussed in Section 2.1, which is in agreement with all authors who have investigated the recovery of carbon fibers through pyrolysis $[5,14,15,22-24,30]$.

The images obtained by scanning electron microscopy (SEM) of the solids obtained in the E1 and E2 experiments is shown in Figure 2. The figure clearly shows that undecomposed resin remains partially covering the fibers in the solid obtained after pyrolysis when the heating rate was $15^{\circ} \mathrm{C} \mathrm{min}-1$ (E1, a figure). However, better elimination of the polymer can be observed in the solid pyrolyzed at $3{ }^{\circ} \mathrm{C} \mathrm{min}{ }^{-1}$ heating rate (E2, b figure). This fact reinforces the utilization of slow pyrolysis in the recycling of CFRP, given that the liquids and vapors obtained are better than those of the conventional pyrolysis, especially when thermo-catalytic treatment is used. Small particles, which are most probably char, can be seen in both SEM images, coming from the carbonization of the resin, as explained above.

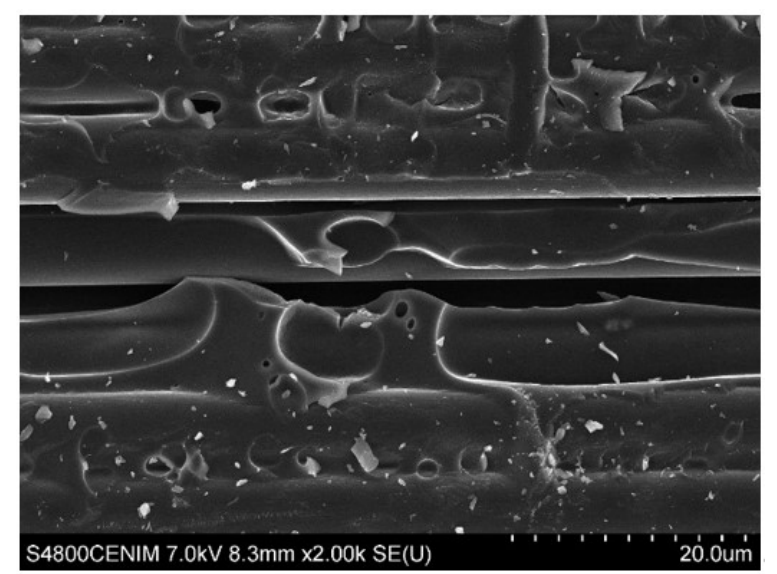

(a)

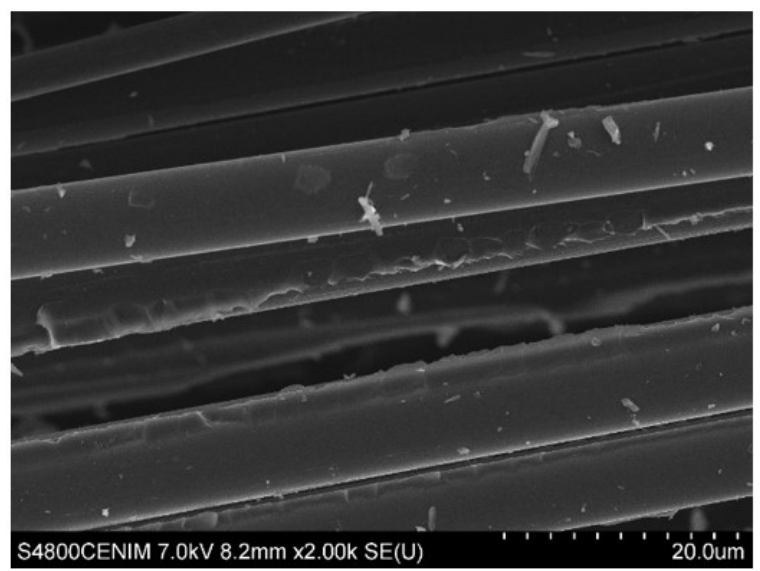

(b)

Figure 2. Scanning electron microscopy (SEM) images of the pyrolysis solids obtained at $15^{\circ} \mathrm{C} \mathrm{min}^{-1}$ (a) and at $3{ }^{\circ} \mathrm{C} \min ^{-1}(\mathbf{b})$.

Figure 3 shows the surface topography of the pyrolysis solids obtained by means of atomic force microscopy (AFM). These images confirm what has been observed in Figure 2. The surface of the pyrolysis solid obtained at $15{ }^{\circ} \mathrm{C} \mathrm{min}^{-1}$ (a) presents a mostly homogeneous area, with low roughness, together with a small section of high roughness. The homogeneous area can indicate the presence of undecomposed resin, whereas the rough section could be big char particle or thicker undecomposed resin. In the solid obtained at $3{ }^{\circ} \mathrm{C} \min ^{-1}(b)$, the roughness is lower, but very homogeneously distributed. This may indicate that we are observing the inherent roughness of a cleaner fiber, without resin. 


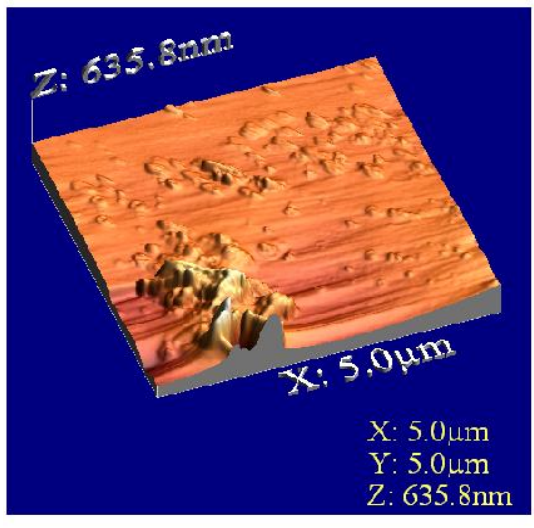

(a)
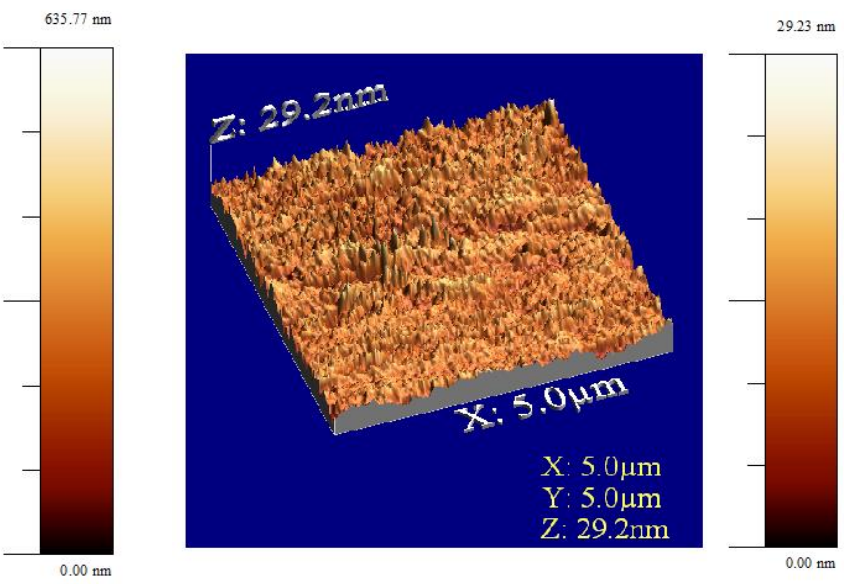

(b)

Figure 3. Atomic force microscopy (AFM) images $(5 \times 5 \mu \mathrm{m})$ of the pyrolysis solids obtained at $15^{\circ} \mathrm{C} \min ^{-1}(\mathbf{a})$ and at $3{ }^{\circ} \mathrm{C} \min ^{-1}(\mathbf{b})$.

The main parameters of surface roughness are collected in Table 4 . The roughness parameters of the initial CFRP have also been included in the table, with the intention of using them as a reference. The arithmetical mean deviation ( $\mathrm{Ra}$ ) is the most used amplitude parameter and shows the vertical deviations of the roughness profile from the mean line. Based on this parameter and looking at the table, it can be said that the initial CFRP has the lowest surface roughness, followed by the E1 pyrolysis solid and then by the E2 solid. These results confirm the fact observed in the images above. The initial CFRP has a low roughness because it is a finished product covered by the resin; then, the surface roughness increases as the polymer resin is being removed due to defects that are created on the surface and the apparition of char particles. This is the reason why E2 solids present higher surface roughness than E1 solids. This tendency is also observed in the values of the maximum valley depth (Rv); a higher value indicates a less rough surface. The third roughness parameter, the maximum peak height (Rp), maintains the tendency between E1 and E2 solids, but in this case, the highest value corresponds to the initial CFRP. However, this value may be affected by the great deviation in the measure $( \pm 3.83 \mu \mathrm{m})$.

Table 4. Main parameters of surface roughness of pyrolysis solids and the initial CFRP.

\begin{tabular}{cccc}
\hline Parameter & E1 Solid & E2 Solid & Initial CFRP \\
\hline Arithmetical mean deviation, $\mathrm{Ra}(\mu \mathrm{m})$ & $1.69 \pm 0.27$ & $1.84 \pm 0.19$ & $1.23 \pm 0.34$ \\
Maximum peak height, $\mathrm{Rp}(\mu \mathrm{m})$ & $5.60 \pm 1.03$ & $6.88 \pm 1.46$ & $7.82 \pm 3.83$ \\
Maximum valley depth, Rv $(\mu \mathrm{m})$ & $-6.52 \pm 1.27$ & $-6.98 \pm 1.80$ & $-6.46 \pm 2.65$ \\
\hline
\end{tabular}

By the data and images collected in Tables 3 and 4, and Figures 2 and 3, it can clearly be stated that the carbon fibers coming from the pyrolysis step still contain undecomposed resin and char particles. The char and the undecomposed resin must be completely eliminated in order to avoid problems in the adhesion between the recovered fibers and the new resin when reusing the fibers in new composite manufacturing. Normally, a controlled oxidation stage is used for this purpose [5,24,30]. In any case, the good performance of the fibers recovered by pyrolysis-oxidation in new composites has been demonstrated by several authors and there are even commercial products available on the market [10]. 


\section{Materials and Methods}

\subsection{CFRP Sample and Catalysts}

The residual CFRP used in this work is an expired pre-impregnated form from the aeronautical industry composed of a poly(benzoxazine) resin and reinforced with Toray T300/3k carbon fibers of $7 \mu \mathrm{m}$ diameter. Pre-impregnation is a specific reinforcing fiber configuration (veil, fabric, unidirectional, etc.) which has been impregnated with a resin well before the time of use. The matrix is only partially cured to allow easy handling. This is known as B-stage polymerization and requires cold storage, usually at $-18{ }^{\circ} \mathrm{C}$, to prevent complete curing. When these materials go a certain amount of time unused or out of storage conditions, they are considered expired. Poly(benzoxazine) is a type of unconventional phenolic resin, which combines some of the best properties of the phenolic resins: thermal and flame-retardant with good mechanical and electrical properties [17,31]. For these reasons, the use of benzoxazines is expected to grow significantly in the future, especially in industrial applications [32]. The sample is received in the form of sheets, which are cut into strips of $20 \mathrm{~cm} \times 2 \mathrm{~cm}$ before being introduced to the pyrolysis reactor (see Figure 4).

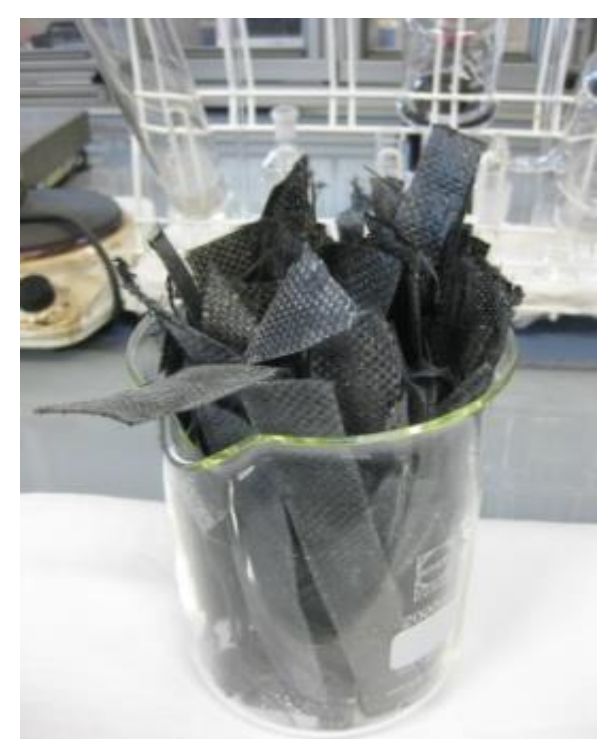

Figure 4. Residual CFRP sample before pyrolysis.

Two types of catalysts have been used in this work: a commercial reforming catalyst and a ZSM-5 type commercial zeolite modified with nickel. The reforming catalyst is commonly employed in industrial reforming processes of natural gas, light hydrocarbons and hydrogen-rich streams. It is a non-alkalized nickel oxide $(\mathrm{NiO} 16 \mathrm{wt} . \%=\mathrm{Ni} 12.6 \mathrm{wt} . \%)$ on a $\mathrm{CaO} / \mathrm{Al}_{2} \mathrm{O}_{3}$ support. This catalyst was used as received. The commercial zeolite is the ZSM-5 CBV 5524G product of Zeolist International, consisting of a $\mathrm{SiO}_{2} / \mathrm{Al}_{2} \mathrm{O}_{3}$ mixture in 57.3:1 mole ratio. This product has the $\mathrm{NH}_{4}^{+}$cationic form, so it was calcined at $500{ }^{\circ} \mathrm{C}$ for $3 \mathrm{~h}$ in order to be transformed into the $\mathrm{H}^{+}$cationic form. Subsequently, $13 \%$ by weight of nickel (nominal) was added to the zeolite through the wet impregnation method [33], with the aim of obtaining a similar nickel content to that of the reforming catalyst. Table 5 presents a summary of the main properties of these two catalysts. Detailed information on the characterization, as well as discussion of the results obtained, can be found in an article previously published by the authors [33]. 
Table 5. Main properties of the catalysts used in this work.

\begin{tabular}{ccc}
\hline Property & Reforming Catalyst & Ni/HZSM-5 \\
\hline BET surface area $\left(\mathrm{m}^{2} / \mathrm{g}\right)$ & 29.0 & 273.9 \\
Total pore volume $\left(\mathrm{cm}^{3} / \mathrm{g}\right)$ & 0.1312 & 0.3887 \\
Average pore diameter $(\AA)$ & 179.3 & 70.7 \\
Measured Ni content $(\mathrm{wt} . \%)$ & 12.5 & 11.0 \\
Ni crystal size $(\mathrm{nm})$ & 5.0 & 4.5 \\
Main reduction peak temperature $\left({ }^{\circ} \mathrm{C}\right)$ & $\approx 700$ & $\approx 350$ \\
Total acidity $\left(\mathrm{mmol} \mathrm{NH}_{3} / \mathrm{g}\right.$ cat) & 0.205 & 0.471 \\
\hline
\end{tabular}

The two catalysts were then impregnated into monolithic cordierite carriers $(400 \mathrm{cpsi}, 2 \times 2 \mathrm{~cm}$, $51.4 \% \mathrm{SiO}_{2}, 30.8 \% \mathrm{Al}_{2} \mathrm{O}_{3}, 13.8 \% \mathrm{MgO}$ ) through the incipient wetness impregnation (IWI) method [34] and these monoliths were placed in the vapor treatment reactor. Monolithic carriers are commonly used in catalytic treatments of gaseous mixtures that can partially condense, since the traditional catalytic beds could be easily blocked. The monoliths are made by parallel sheets, allowing an easy flow of the mixture, but keeping a high surface area [35]. These sheets may be directly made of the active metal or can be made by an inert material and later impregnated with the catalyst, as explained above. In this work, the quantity of catalyst impregnated in the monoliths was $0.6 \mathrm{~g}$, which approximately corresponds to the $2.5 \mathrm{wt} . \%$ of the vapors to be treated. Before starting the experiments, catalysts were reduced at $800{ }^{\circ} \mathrm{C}$ during $4 \mathrm{~h}$ in the presence of a mixture containing $10 \% \mathrm{H}_{2}, 10 \% \mathrm{~N}_{2}$ and $80 \% \mathrm{Ar}$ in volume.

\subsection{Pyrolysis Installation}

The thermal treatment of the residual pre-impregnation is carried out in a lab-scale plant consisting of two reactors in series (pyrolysis reactor and vapor treatment reactor) and a cooling and condensation section (see Figure 5).

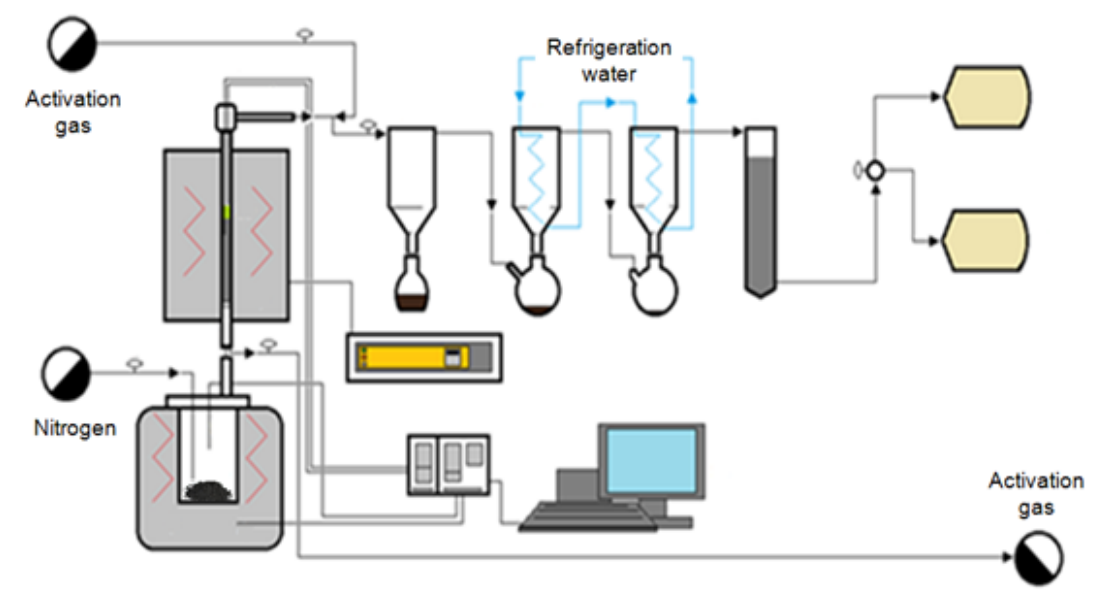

Figure 5. Lab-scale plant for the pyrolysis and vapors treatment of waste CFRP.

The pyrolysis reactor (bottom-left part of the Figure 5) is a non-stirred tank reactor of $3.5 \mathrm{~L}$ capacity, externally heated with an electric furnace. In all the experiments of the present work, this reactor is loaded with $100 \mathrm{~g}$ of residual pre-impregnation, which are heated up from ambient temperature to $500{ }^{\circ} \mathrm{C}$ and then maintained for $30 \mathrm{~min}$ at this temperature.

In the vapor treatment reactor, the vapors generated in the decomposition of the resin are thermo-catalytically treated. This reactor is filled with silicon carbide ( $\mathrm{SiC}$ ) particles $(1.5 \mathrm{~mm}<$ diameter $<3.2 \mathrm{~mm})$ in order to improve the fluid dynamics of the system, generating a better mixture of compounds, and also improving the thermal conductivity of the bed for a quick heat transfer between the walls of the reactor and the bed to ensure no temperature gradients. Besides, the packing 
allows the gas to move tortuously, guaranteeing good lateral mixing and avoiding concentration gradients. In the case of using a catalyst, the packing enhances the gas-catalyst contact [36]. Apart from $\mathrm{SiC}$ particles, three monolithic cordierite ceramic carriers $(400 \mathrm{cpsi}, 2 \times 2 \mathrm{~cm})$ are placed in the reactor (see Figure 6). One in the bottom in order to hold the filling, another one on the top with the aim of preventing the flow of gases from expelling particles of $\mathrm{SiC}$, and the third one impregnated with the catalyst in the middle of the reactor. The temperature of this reactor in all the experiments presented in this paper is $900{ }^{\circ} \mathrm{C}$. Both reactors are swept with $1 \mathrm{~L} / \mathrm{min}$ flow of $\mathrm{N}_{2}$ during the whole experiment. In the cooling and condensation section, consisting of three condensers, the generated vapors and gases undergo a cooling process in which some compounds partially condense. The non-condensable gases are passed through an active carbon bed before being collected in bags.

Five different experiments have been carried out in the present work: first, two experiments without the vapor treatment reactor, done with the aim of knowing the nature of the CFRP pyrolysis process and studying the influence of the heating rate in it (E1 and E2). In the last three experiments, the thermal and thermo-catalytic treatment of pyrolysis vapors and gases is tested with the lower heating rate (E3, E4 and E5).

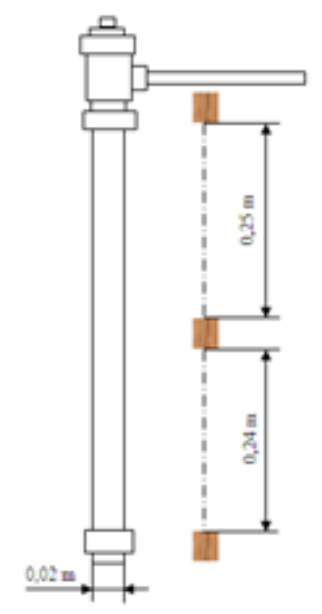

Figure 6. Internal structure of the tubular reactor where the monoliths were placed.

The pyrolysis yields are the mean value of at least two experiments that do not differ by more than $3 \mathrm{wt} . \%$ from one to another. These yields are quantified as follows: the solid yield is calculated by weighing the remaining solid after the pyrolysis process, the total condensates are determined by the weight difference found in the pipes, reactors and condensers of the installation before and after each experiment, and the gas yield is determined by difference. The liquids collected in the condensers are part of "total condensates" but they have been quantified and distinguished as "collected liquids", with the aim of giving representative information about the process parameters more than of the installation geometry itself, which can influence the generation of condensates in pipes and other elements. The collected liquids have been used to determine the proportion of aqueous and organic fractions.

\subsection{Analytical Techniques}

The thermal behavior of the initial sample was determined by a Mettler Toledo TGA/SDTA851 thermo-balance (Columbus, OH, USA) through a dynamic analysis consisting of heating $10 \mathrm{mg}$ of sample at a rate of $10{ }^{\circ} \mathrm{C} \mathrm{min}-1$ up to $1000{ }^{\circ} \mathrm{C}$ in the presence of $50 \mathrm{~mL} \mathrm{~min}^{-1}$ of $\mathrm{N}_{2}$. The temperature of the maximum degradation rate was determined from the first derivative thermogravimetric plot (DTG). The fiber volume was obtained by applying the standardized method ASTM D3171, which consists of chemical oxidation of the resin with $\mathrm{H}_{2} \mathrm{SO}_{4}$ and $\mathrm{H}_{2} \mathrm{O}_{2}$. This sample was also characterized by proximate analysis (moisture, volatiles, fixed carbon and ash) and elemental analysis $(\mathrm{C}, \mathrm{H}, \mathrm{N}$, and $\mathrm{S}$ ). The first was performed using the thermogravimetric balance LECO TGA-500 (LECO, St. Joseph, MI, 
USA), according to ASTM standards D3173-85 and D3174-82, and the second by using the automatic analyzers LECO TrueSpec CHN (LECO, St. Joseph, MI, USA) and TrueSpec S (LECO, St. Joseph, MI, USA). Additionally, Method 5050 from the Environmental Protection Agency (EPA) was applied for the determination of chlorine in solid waste.

The composition of the liquids obtained in the pyrolysis was analyzed using the AGILENT 6890 gas chromatograph (AGILENT, Santa Clara, CA, USA) with the AGILENT 5973 mass detector (GC-MS). The following criterion is used for the processing of the data obtained: a chemical compound is considered to be well identified when the identification quality parameter given by the chromatograph software is greater than $85 \%$. Below this value, compounds are considered as unidentified. Pyrolysis gas composition was determined by the AGILENT 7890A gas chromatograph (GC) equipped with two detectors: a thermal conductivity detector and a flame ionization detector (GC-TCD/FID). The GC was calibrated using a "refinery blend" standard provided by Air Liquide. The given composition is shown on a $\mathrm{N}_{2}$ - and water-free basis and the HHV was calculated from the HHV of the pure components. The solid products obtained in the tests were characterized by proximate and elemental analyses. The surface morphology and topography of solids was analyzed by scanning electron microscopy (SEM) and by atomic force microscopy (AFM). The morphology was studied using a JEOL JSM 7600 apparatus (Tokio, Japan). Atomic force microscopy (AFM) observations were made in an AGILENT $5500 \mathrm{AFM} / \mathrm{SPM}$ microscope (Santa Clara, CA, USA) in tapping mode. Images show the topography of a scan over an area of $5 \times 5 \mu \mathrm{m}$. The roughness was measured in the $5 \times 5 \mu \mathrm{m}$ AFM images after mean plane subtraction with the program Gwyddion. Surface topographies were examined, and roughness Ra values were obtained using an optical imaging profiler PL 42300 (SENSOFAR, Barcelona, Spain) operated at $20 \times$. The profiles combine confocal and interferometry techniques with a sub-nanometer resolution. The cited Ra values (Table 4) are an average of 50 measurements with standard error of the mean $<5 \%$.

\section{Conclusions}

In this research work, it has been demonstrated that it is possible to valorize the material value of the polymeric resin of waste CFRP through the thermo-catalytic treatment of the vapors generated during resin decomposition. The thermal treatment (thermal cracking) makes it possible to reduce the amount of condensates and the organic fraction by half (the collected liquids are reduced by $90 \%$ ) and promotes the formation of $\mathrm{H}_{2}$ in the produced gases. The use of acid-supported reforming catalysts converts the organic fraction into a negligible by-product and generates hydrogen by means of reforming the hydrocarbons (such as the organic liquids and gaseous hydrocarbons). It has been observed that when the catalyst support is very acidic, e.g., zeolite type, hydrogen is also generated by catalytic cracking, which allows more than half of the hydrogen in the resin to be recovered in the form of $\mathrm{H}_{2}$, ranging from more than 56 vol.\% in the gases. Such a proportion of $\mathrm{H}_{2}$ makes it possible to separate this compound from the rest of the gases, allowing the hydrogen to be another product of the process, in addition to the carbon fibers. Although the performance of the catalysts and the economic impact of the treatment on the process have yet to be further investigated, it appears that this investigation will be the starting point for future works on the recovery of chemical compounds from CFRP polymer resins.

\section{Patents}

The experimental work presented in this article is part of the Spanish Patent "Method for treating vapours generated during the process for recovering carbon fibres from composites by pyrolysis", with ID number 201530223. The patent has also been submitted for evaluation to the European Patent Office (5586678) and to the United States Patent and Trademark Office (15553058), where it is under evaluation.

Author Contributions: Conceptualization, A.L.-U. and I.d.M. Methodology, N.G. and A.L.-U. Validation, N.G. Investigation, N.G., J.S., E.A. and F.A.L. Resources, A.L.-U., F.A.L. and I.d.M. Writing-original draft, A.L.-U. 
Writing—review and editing, E.A., B.M.C., F.A.L. and I.d.M. Visualization, A.L.-U. Supervision, I.d.M. Project administration, I.d.M., F.A.L. and B.M.C. Funding acquisition, I.d.M., F.A.L. and B.M.C.

Funding: This research was funded by the Ministry of Economy and Competitiveness of the Spanish Government, in the 'Research Challenges' call for proposals in 2013 (Ref. CTM2013-48887-C2-1-R and C2-2-R) and by the University of the Basque Country (UPV/EHU) (Ref. PPM 12/11).

Acknowledgments: The authors would like to thank Felisa Laresgoiti for her tireless support, advice and dedication in the laboratory.

Conflicts of Interest: The authors declare no conflict of interest.

\section{References}

1. Callister, W.D.; Rethwisch, D.G. Properties of Selected Engineering Materials (appendix B). In Materials Science and Engineering. An Introduction, 7th ed.; John Wiley \& Sons, Inc.: New York, NY, USA, 2007; pp. A3-A30, ISBN 978-0-471-73696-7.

2. Newcomb, B.A. Processing, structure, and properties of carbon fibers. Compos. Part A-Appl. Sci. Manuf. 2016, 91, 262-282. [CrossRef]

3. Meng, F.; McKechnie, J.; Tuner, T.A.; Pickering, S.J. Energy and environmental assessment and reuse of fluidised bed recycled carbon fibres. Compos. Part A-Appl. Sci. Manuf. 2018, 100, 206-214. [CrossRef]

4. Sloan, J. Carbon Fiber 2016 Report. Compos. World 2017, 3, 24-25. Available online: www.compositesworld. com/articles/carbon-fiber-2016-report (accessed on 28 September 2018).

5. Giorgini, L.; Benelli, T.; Mazzocchetti, L.; Leonardi, C.; Zattini, G.; Minak, G.; Dolcini, E.; Cavazzoni, M.; Montanari, I.; Tosi, C. Recovery of Carbon Fibers From Cured and Uncured Carbon Fiber Reinforced Composites Wastes and Their Use as Feedstock for a New Composite Production. Polym. Compos. 2015, 36, 1084-1095. [CrossRef]

6. Vo Dong, P.A.; Azzaro-Pantel, C.; Cadene, A.L. Economic and environmental assessment of recovery and disposal pathways for CFRP waste management. Resour. Conserv. Recycl. 2018, 133, 63-75. [CrossRef]

7. Pimenta, S.; Pinho, S.T. Recycling carbon fibre reinforced polymers for structural applications: Technology review and market outlook. Waste Manag. 2011, 31, 378-392. [CrossRef] [PubMed]

8. Yang, Y.; Boom, R.; Irion, B.; van Heerden, D.J.; Kuiper, P.; de Wit, H. Recycling of composite materials. Chem. Eng. Process. 2012, 51, 53-68. [CrossRef]

9. Pimenta, S.; Pinho, S.T. Recycling of Carbon Fibers. In Handbook of Recycling, 1st ed.; Worrell, E., Reuter, M.A., Eds.; Elsevier: Waltham, MA, USA, 2014; pp. 269-283, ISBN 978-0-12-396459-5.

10. Black, S. Composites recycling: Gaining traction. Compos. World 2017, 3, 46-55. Available online: www. compositesworld.com/articles / composites-recycling-gaining-traction (accessed on 28 September 2018).

11. Wang, F.C.Y.; Dettloff, M.L.; Null, M.J.; White, J.E. Qualitative and quantitative analysis of a thermoset polymer, poly(benzoxazine), by pyrolysis-gas chromatography. J. Chromatogr. A 2000, 886, 217-244. [CrossRef]

12. Cunliffe, A.M.; Jones, N.; Williams, P.T. Recycling of fibre reinforced polymeric waste by pyrolysis: Thermo-gravimetric and bench-scale investigations. J. Anal. Appl. Pyrolysis 2003, 70, 315-338. [CrossRef]

13. Yang, J.; Liu, J.; Liu, W.; Wang, J.; Tang, T. Recycling of carbon fibre reinforced epoxy resin composites under various oxygen concentrations in nitrogen-oxygen atmosphere. J. Anal. Appl. Pyrolysis 2015, 112, $253-261$. [CrossRef]

14. Nahil, M.A.; Williams, P.T. Recycling of carbon fibre reinforced polymeric waste for the production of activated carbon fibres. J. Anal. Appl. Pyrolysis 2011, 91, 67-75. [CrossRef]

15. López, F.A.; Rodríguez, O.; Alguacil, F.J.; García-Díaz, I.; Centeno, T.A.; García-Fierro, J.L.; González, C. Recovery of carbon fibres by the thermolysis and gasification of waste prepreg. J. Anal. Appl. Pyrolysis 2013, 104, 675-683. [CrossRef]

16. Zhang, J. Different Surface Treatments of Carbon Fibers and Their Influence on the Interfacial Properties of Carbon Fiber/Epoxy Composites. Ph.D. Thesis, National Center for Scientific Research, Paris, France, 2012.

17. Ghosh, N.N.; Kiskan, B.; Yagci, Y. Polybenzoxazines-New high performance thermosetting resins: Synthesis and properties. Prog. Polym. Sci. 2007, 32, 1344-1391. [CrossRef]

18. Zúñiga, C.J. Polybenzoxazine Materials from Renewable Diphenolic Acid. Ph.D. Thesis, Universitat Rovira I Virgili, Tarragona, Spain, 2013. 
19. Beyazkilic, Z.; Kahveci, M.U.; Aydogan, B.; Kiskan, B.; Yagci, Y. Synthesis of Polybenzoxazine Precursors Using Thiols: Simultaneous Thiol-Ene and Ring-Opening Reactions. J. Polym. Sci. 2012, 50, 4029-4036. [CrossRef]

20. Wang, Q.; Ning, H.; Vaidya, U.; Pillay, S.; Nolen, L.A. Development of a carbonization-in-nitrogen method for measuring the fiber content of carbon fiber reinforced thermoset composites. Compos. Part A-Appl. Sci. Manuf. 2015, 73, 80-84. [CrossRef]

21. Irisawa, T.; Inagaki, R.; Iida, J.; Iwamura, R.; Ujihara, K.; Kobayashi, S.; Tanabe, Y. The influence of oxygen containing functional groups on carbon fibers for mechanical properties and recyclability of CFRTPs made with in-situ polymerizable polyamide 6. Compos. Part A-Appl. Sci. Manuf. 2018, 112, 91-99. [CrossRef]

22. Meyer, L.O.; Schulte, K. CFRP-Recycling Following a Pyrolysis Route: Process Optimization and Potentials. J. Compos. Mater. 2009, 43, 1121-1132. [CrossRef]

23. Tranchard, P.; Duquesne, S.; Samyn, F.; Estèbe, B.; Bourbigot, S. Kinetic analysis of the thermal decomposition of a carbon fibre-reinforced epoxy resin laminate. J. Anal. Appl. Pyrolysis 2017, 126, 14-21. [CrossRef]

24. Onwudili, J.A.; Miskolczi, N.; Nagy, T.; Lipóczi, G. Recovery of glass fibre and carbon fibres from reinforced thermosets by batch pyrolysis and investigation of fibre re-using as reinforcement in LDPE matrix. Compos. Part B-Eng. 2016, 91, 154-161. [CrossRef]

25. Solar, J.; de Marco, I.; Caballero, B.M.; Lopez-Urionabarrenechea, A.; Rodriguez, N.; Agirre, I.; Adrados, A. Influence of temperature and residence time in the pyrolysis of woody biomass waste in a continuous screw reactor. Biomass Bioenerg. 2016, 95, 416-423. [CrossRef]

26. Solar, J.; Hernandez, A.; Lopez-Urionabarrenechea, A.; de Marco, I.; Adrados, A.; Caballero, B.M.; Gastelu, N. From woody biomass Waste to biocoke: Influence of the proportion of different tree components. Eur J. Wood Prod. 2017, 75, 485-497. [CrossRef]

27. Adrados, A.; de Marco, I.; Lopez-Urionabarrenechea, A.; Solar, J.; Caballero, B. Avoiding tar formation in biocoke production from waste biomass. Biomass Bioenerg. 2015, 74, 172-179. [CrossRef]

28. Adrados, A.; Lopez-Urionabarrenechea, A.; Solar, J.; Requies, J.; de Marco, I.; Cambra, J.F. Upgrading of pyrolysis vapours from biomass carbonization. J. Anal. Appl. Pyrolysis 2013, 103, 293-299. [CrossRef]

29. Solar, J.; Caballero, B.M.; de Marco, I.; Lopez-Urionabarrenechea, A.; Gastelu, N. Optimization of charcoal production process from woody biomass waste: Effect of Ni-containing catalysts on pyrolysis vapors. Catalysts 2018, 8, 191. [CrossRef]

30. Mazzocchetti, L.; Benelli, T.; D'Angelo, E.; Leonardi, C.; Zattini, G.; Giorgini, L. Validation of carbon fibers recycling by pyro-gasification: The influence of oxidation conditions to obtain clean fibers and promote fiber/matrix adhesion in epoxy composites. Compos. Part A-Appl. Sci. Manuf. 2018, 112, 504-514. [CrossRef]

31. Gu, Y.; Ran, Q.C. Polybenzoxazine/Fiber Composites. In Handbook of Benzoxazine Resins, 1st ed.; Ishida, H., Agag, T., Eds.; Elsevier: Waltham, MA, USA, 2011; pp. 481-494, ISBN 9780444537911.

32. Sawaryn, C.; Kreiling, S.; Schönfeld, R.; Landfester, K.; Taden, A. Benzoxazines for Industrial Applications Comparison with Other Resins, Formulation and Toughening Know-How, and Water-Based Dispersion Technology. In Handbook of Benzoxazine Resins, 1st ed.; Ishida, H., Agag, T., Eds.; Elsevier: Waltham, MA, USA, 2011; pp. 605-620, ISBN 9780444537911.

33. Adrados, A.; Lopez-Urionabarrenechea, A.; Acha, E.; Solar, J.; Caballero, B.M.; de Marco, I. Hydrogen rich reducing gases generation in the production of charcoal from woody biomass carbonization. Energy Convers. Manag. 2017, 148, 352-359. [CrossRef]

34. Haber, J.; Block, J.H.; Delmon, B. IUPAC Technical Reports. Manual of methods and procedures for catalyst characterization. Pure Appl. Chem. 1995, 67, 1257-1306. [CrossRef]

35. Fogler, H.S. Elements of Chemical Reaction Engineering, 5th ed.; Prentice Hall: New Jersey, NJ, USA, 2016; ISBN 9780133887518.

36. Ross, J. Heterogeneous Catalysis: Fundamentals and Applications, 1st ed.; Elsevier: Waltham, MA, USA, 2011; ISBN 9780444638403.

(C) 2018 by the authors. Licensee MDPI, Basel, Switzerland. This article is an open access article distributed under the terms and conditions of the Creative Commons Attribution (CC BY) license (http:/ / creativecommons.org/licenses/by/4.0/). 